prn, for depression, oppositional defiance, and learning disorder; he collapsed and died in cardiac arrest after running several blocks home from school. Autopsies in both patients revealed no cardiovascular or brain abnormalities. Tricyclic antidepressant blood levels were $2000 \mathrm{ng} / \mathrm{ml}$ (case 1), and 10000 $\mathrm{ng} / \mathrm{ml}$ (case 2). (Varley CK, McClellan J. Case study: Two additional sudden deaths with tricyclic antidepressants. I Am Acad Child Adolesc Psychiatry March 1997;36:390-394). (Reprints: Dr Varley, Department of Child Psychiatry, CL-08, Children's Hospital and Medical Center, PO Box 5371, Seattle, WA 98105).

COMMENT. The authors cite 5 reported cases since 1990 of sudden death in children treated with desipramine. One additional case involving desipramine and one with imipramine are reported. The actual risk of cardiac arrest associated with tricyclic antidepressants in children is unknown but is probably underreported. Informed consent and cardiac monitoring are advised, and the authors question the use of desipramine as a first-line antidepressant in children.

\title{
ANALYSIS OF PEMOLINE-ASSOCIATED HEPATIC FAILURE
}

A search of online computerized medical data-bases (Medline, Peruse) at McGill University, Montreal, Canada, revealed four reported cases of fatal fulminant hepatic failure (FHF) associated with pemoline (Cylert) use as a treatment for attention deficit hyperactivity disorder. Transient increases in hepatic enzymes, with or without symptoms of hepatitis, have been reported in several articles. Of the four reported cases of FHF, one was a deliberate pemoline overdose, one had preexisting cirrhosis, a third developed FHF after addition of methylphenidate (MPH), and one had taken pemoline alternating with MPH for 5 years and pemoline alone for one year. Of these cases, only one appeared justified. The risk of hepatic failure with pemoline may have been overemphasized, but precautions with its use are advised. (Shevell M, Schreiber R. Pemoline-associated hepatic failure: a critical analysis of the literature. Pediatr Neurol Jan 1997;16:14-16). (Respond: Dr Shevell, A-514, Montreal Children's Hospital, 2300 Tupper, Montreal, Quebec, Canada H3H 1P3).

COMMENT. Since the presentation of this article for publication, Abbott Laboratories has notified practitioners of the concern regarding further cases of pemoline associated hepatic failure, and the FDA has advised that pemoline should not be prescribed as a first line treatment for ADHD. Preexisting liver disease is a contraindication, and polytherapy with methylphenidate should be avoided. Baseline and monthly routine liver function monitoring are probably advisable, although the value of this screening in prediction and prevention of hepatic failure is unproven. Significant increases in liver enzymes or symptoms of hepatic dysfunction, such as nausea, anorexia, vomiting, and jaundice, are indications for immediate withdrawal of pemoline treatment. The authors propose a central registry for cases of pemoline-associated hepatic failure.

Amantadine hydrochloride, a dopamine agonist, adjunct treatment for ADHD, is reported of value in 30 children who failed to respond to stimulant therapy. The doses employed were $75 \mathrm{mg}$ bid in liquid form $(50 \mathrm{mg} / 5 \mathrm{ml})$, for children 8 years of age and younger, and $100 \mathrm{mg}$ bid as $100 \mathrm{mg}$ capsules, for children 9 years of age and older. Advantages of amantadine over tricyclic antidepressants and antihypertensive agents used as adjunct therapies for ADHD include freedom from cardiovascular effects and effects on appetite, and lack of daytime sedation. Vivid dreams were the only 
side effect witnessed by the author. Further controlled trials are indicated. (Masters KJ. Alternative medication for ADHD. Letter to editor. I Am Acad Child Adolesc Psychiatry March 1997;36:301).

\section{VASCULAR DISORDERS}

\section{IRON DEFICIENCY AND STROKE}

A series of six iron deficient children, 6 to 18 months of age, presenting with an ischemic stroke or venous thrombosis after a viral syndrome, are reported from the University of Saskatchewan, and the Children's Hospital of Eastern Ontario, Canada. Other known etiologies for stroke were excluded. Iron deficiency, in association with a nonspecific viral illness, was a contributing factor and not a coincidental finding. (Hartfield DS, Lowry NJ, Keene DL, Yager JY. Iron deficiency: a cause of stroke in infants and children. Pediatr Neurol Jan 1997;16:50-53). (Respond: Dr Yager, Room 3717, F Wing, Department of Pediatrics, Royal University Hospital, 103 Hospital Drive, Saskatoon, Saskatchewan, Canada S7N 0W8).

COMMENT. Iron deficiency anemia in infancy and early childhood can be a contributing factor in the etiology of stroke. Iron deficiency has also been related to other neurological illness, including breath holding spells, headache, pseudotumor, diplopia, and cranial nerve palsies. (see Progress in Pediatric Neurology I, PNB Publ, Chicago, 1991;pp397-398).

\section{INFECTIOUS DISORDERS}

\section{TREATMENT OF RAMSAY HUNT SYNDROME}

The effect of acyclovir-prednisone treatment in 80 patients with Ramsay Hunt syndrome was analyzed retrospectively at the Department of Otolaryngology, Ehime University School of Medicine, Ehime, Japan. Ages ranged from 15 to 75 years. All presented with facial paralysis and herpetic eruption on the pinna or oral mucosa, and 22 had associated hearing loss. Treatment with acyclovir, $250 \mathrm{mg}$ tid by intravenous drip or $800 \mathrm{mg} 5 \mathrm{x}$ daily orally, and prednisone, $1 \mathrm{mg} / \mathrm{kg}$ day iv or orally, was started 1 to 10 days after onset of facial paralysis. Recovery from paralysis was complete in $21(75 \%)$ of 28 patients treated within 3 days of onset, and in only 7 (30\%) of 23 whose treatment was delayed more than 7 days. Nerve excitability testing showed that nerve degeneration was reduced by early administration of acyclovirprednisone therapy. Recovery of hearing was better in patients treated early. In facial nerve recovery and outcome, intravenous administration of acyclovir was not superior to oral treatment. (Murakami S, Hato N, Horiuchi J et al. Treatment of Ramsay Hunt syndrome with acyclovir-prednisone: significance of early diagnosis and treatment. Ann Neurol March 1997;41:353357). (Respond: Dr Murakami, Department of Otolaryngology, Ehime University School of Medicine, Shigenobu-cho, Onsen-gun, Ehime 791-02, Japan).

COMMENT. Ramsay Hunt syndrome manifested by facial pain and nerve paralysis, herpetic eruption on the pinna, and frequent vestibulocochlear involvement, is caused by varicella-zoster virus infection. Early administration of acyclovir and prednisone, within the first 3 days of onset, results in $75 \%$ rate of facial nerve recovery and less likelihood of residual nerve deafness. Absence of herpetic eruption in 8 to $25 \%$ of cases leads to misdiagnosis as Bell's palsy and poorer prognosis because acyclovir treatment 